\title{
Tissue Slice Grafts
}

\section{An in Vivo Model of Human Prostate Androgen Signaling}

\author{
Hongjuan Zhao, Rosalie Nolley, Zuxiong Chen, \\ and Donna M. Peehl \\ From the Department of Urology, Stanford University School of \\ Medicine, Stanford, California
}

We developed a tissue slice graft (TSG) model by implanting thin, precision-cut tissue slices derived from fresh primary prostatic adenocarcinomas under the renal capsule of immunodeficient mice. This new $i n$ vivo model not only allows analysis of approximately all of the cell types present in prostate cancer within an intact tissue microenvironment, but also provides a more accurate assessment of the effects of interventions when tissues from the same specimen with similar cell composition and histology are used as control and experimental samples. The thinness of the slices ensures that sufficient samples can be obtained for large experiments as well as permits optimal exchange of nutrients, oxygen, and drugs between the grafted tissue and the host. Both benign and cancer tissues displayed characteristic histology and expression of cell-type specific markers for up to 3 months. Moreover, androgen-regulated protein expression diminished in TSGs after androgen ablation of the host and was restored after androgen repletion. Finally, many normal secretory epithelial cells and cancer cells in TSGs remained viable 2 months after androgen ablation, consistent with similar observations in postprostatectomy specimens following neoadjuvant androgen ablation. Among these were putative $\mathrm{Nkx} 3.1^{+}$stem cells. Our novel TSG model has the appropriate characteristics to serve as a useful tool to model all stages of disease, including normal tissue, premalignant lesions, well-differentiated cancer, and poorly differentiated cancer. (Am J Pathol 2010, 177:229-239; DOI: 10.2353/ajpath.2010.090821)

Over the years, significant efforts have been made to develop realistic model systems to investigate the biology of benign and malignant prostatic epithelial cells. These models are vital in prostate research and have enabled important discoveries. However, there are intrinsic limitations in these experimental models that limit their use. ${ }^{1}$ For example, most of the immortal cell lines maintain little of the secretory differentiation that is characteristic of normal and cancerous epithelial cells of the prostate. Many do not express androgen receptor (AR) or prostate specific antigen (PSA), or express a mutated $A R{ }^{2,3}$ Similarly, primary cultures derived from normal or cancer tissues typically lose functional AR and androgensensitive growth and gene expression. ${ }^{4}$ Their limited life span also makes it difficult to generate sufficient cells for long-term studies. ${ }^{4}$ Moreover, the interactions between the epithelial, stromal, and vascular compartments of the prostate, which have been demonstrated to be essential for normal prostate development and function as well as in the development and progression of prostate cancer (PCa), are also missing in these in vitro model systems. ${ }^{1}$

Commonly used in vivo models of human PCa such as xenografts generated from cell lines suffer similar drawbacks of lack of expression of wild-type AR and/or the complex biochemical and physical interactions between the various cellular, tissue, and hormonal compartments that characterize human $\mathrm{PCa}$. Animal models of $\mathrm{PCa}$ such as transgenic and knock-out mouse models maintain an intact prostate architecture; however, these systems do not model the progression of human PCa because the single molecule transgenic and knock-out mice either rarely develop a pathology beyond hyperplasia or prostatic intraepithelial neoplasia or rapidly progress to poorly differentiated cancer. ${ }^{5}$ In addition, differences in the anatomy and physiology between the rodent and human prostate also make it difficult to generalize conclusions obtained by using these models. ${ }^{6}$

Xenografts derived from direct implantation of small pieces of tumors freshly taken from patients into mice, so-called "tumorgrafts," are thought to be the most real-

Supported by National Institutes of Health/NCI (CA123532) to H.Z. and (CA121460) to D.M.P. and a Prostate Cancer Foundation Challenge Award to D.M.P.

Accepted for publication March 22, 2010.

Address reprint requests to Donna M. Peehl, Ph.D., Department of Urology, Stanford University School of Medicine, Stanford, CA 943055118. E-mail: dpeeh!@stanford.edu. 
istic experimental models of human cancer because they recapitulate the parent tumors microscopically as well as molecularly. ${ }^{7}$ In several malignancies, tumorgrafts have gained popularity recently because they are very predictive of drug response. ${ }^{8}$ The ability to generate prostate tumorgrafts has been demonstrated by several groups. ${ }^{9-13}$ The take rate of prostate tumorgrafts under the renal capsule of immunodeficient mice is $>90 \%$ using a recently optimized protocol. ${ }^{10}$ This model has been used to compare angiogenesis in PCa versus benign prostate and to quantify apoptotic activity after castration in human prostate tissue. ${ }^{11,13}$

Androgen signaling plays a key role not only in the growth and function of normal prostate, but also in the development and progression of PCa. ${ }^{14}$ Androgen deprivation therapy is a common treatment for men with advanced $\mathrm{PCa} .{ }^{15}$ Prostate tissue grafts have been used to determine the response of benign and cancerous tissues to androgen deprivation. ${ }^{12,13}$ It was reported that benign glandular structures in postcastration grafts were populated by basal, secretory, and squamous cells, whereas cancer glands in the grafts resembled the original cancer tissue. ${ }^{12}$ However, it is not clear whether androgen signaling is decreased in castrated grafts and whether the pathway activity can resume after androgen restoration.

We have modified the "tumorgraft" model by the use of thin, precision-cut tissue slices. This protocol extends previous applications of such tissue slices in vitro. ${ }^{16-18}$ This new in vivo model not only allows analysis of approximately all of the cell types present in PCa within an intact tissue microenvironment, but also provides a more accurate assessment of the effects of interventions when tissues from the same specimen with similar cell composition and histology are used as control and experimental samples. The thinness of the slices ensures that sufficient samples can be obtained for large experiments as well as permits optimal exchange of nutrients, oxygen, and drugs between the grafted tissue and the host. Using this model, we investigated the responses of prostate tissue to androgen ablation and restoration.

\section{Materials and Methods}

\section{Patient Samples}

Two histologically confirmed cancer tissues from radical prostatectomy specimens were used to generate tissue slice grafts (TSGs). Both tissues contained cancer of Gleason grade 4. Neither patient had prior chemical, hormonal, or radiation therapy.

\section{Precision-Cutting of Tissue Slices}

Putative cancers were grossly identified in two radical prostatectomy specimens obtained immediately after surgery under an Institutional Review Board-approved protocol. With an automated coring device (Alabama Research and Development, Mundford, AL) under aseptic conditions, 5-mm diameter cores were bored from the putative cancers and submerged in ice-cold HEPES- buffered saline. A Krumdieck tissue slicer (Alabama Research and Development) was used to prepare precision-cut tissue slices according to the manufacturer's instructions. Specifically, each tissue core was encased in 3\% sterile agarose (EMD Chemicals Inc., Hawthorne, NY) inside a mold-plunger assembly specifically devised for tissue embedding before slicing. The embedded tissues were then transferred into the slicer filled with precooled HEPES-buffered saline, and 300- $\mu \mathrm{m}$ slices were cut one at a time. Each slice was collected and submerged in ice-cold HEPES-buffered saline in serially numbered tubes.

\section{Subrenal Implantation of Tissue Slices}

All animal studies were done in compliance with the regulations for animal studies at Stanford University. Each male recombination activating gene-2 (RAG2) ${ }^{-1-} \gamma \mathrm{C}^{-1-}$ mouse between 6 and 8 weeks of age was anesthetized and maintained under a heating lamp during the procedure. Sterile practices were followed throughout the surgical procedure. The skin at the incision site was shaved and sterilized with three scrubs of povidone iodine. A short incision was made with a scalpel immediately over the kidney. The kidney was gently popped through the incision and kept moist with sterile physiological saline. A small hole in the renal capsule was made with forceps and raised to create a small pocket between the capsule and the underlying kidney tissue. Into this pocket, a tissue slice $(5 \mathrm{~mm} \times 0.3 \mathrm{~mm})$ was inserted with forceps. The renal capsule was released and allowed to cover the inserted tissue slice. The kidney was gently popped back through the incision, and the body wall was sutured. The skin incision was sealed with wound clips. A $25-\mathrm{mg}$ testosterone pellet was inserted into a small incision made under the skin between the shoulder blades. The release rate of such pellets is approximately $0.2 \mathrm{mg} /$ day. ${ }^{19,20}$

\section{Castration of Mice}

The skin of the scrotal sacs was shaved and sterilized with three scrubs of povidone iodine. Both testes were pushed down into the scrotal sacs by gently applying pressure to the abdomen, and an incision $(\sim 1 \mathrm{~cm})$ was made through the skin along the midline of the scrotal sac. The midline wall between the testes sacs under the covering membranes was then located and a 5-mm incision in the membrane on the left side of the midline was made. The testis was carefully pushed out. A 4-0 Vicryl absorbable suture was used to ligate the vessels going to and from the testis. The fat pad that adheres to the testis was grasped with blunt forceps, and the testis was dissected away and removed from the fat pad. After pushing back the fat pad into the scrotal sac, the incision was closed with 4-0 Vicryl absorbable suture. The remnant of the testosterone pellet was then located and removed from the mouse. 


\section{Immunohistochemistry}

Mice were sacrificed and host kidneys carrying tissue slice grafts were fixed in $10 \%$ buffered formalin overnight and embedded in paraffin. Five-micron sections were cut from the blocks. Tissue sections were deparaffinized with xylene and rehydrated with ethanol. Antigen retrieval was performed for 20 minutes by heating in a citrate buffer ( $\mathrm{pH}$ 6.0), followed by a 20-minute cool-down. Endogenous peroxidase activity was blocked by incubation in methanol containing $0.3 \%$ hydrogen peroxide. After preincubation with 10\% horse serum for 20 minutes at room temperature to block nonspecific binding of antibodies, the tissues were incubated overnight at $4^{\circ} \mathrm{C}$ with primary antibodies against cytokeratin 18 (K18), AR, high molecular weight cytokeratins (HMWK), PSA, p63, Ki-67, cleaved caspase 3 (Biocare Medical, Concord, CA), Ku70 (Abcam, Cambridge, MA), human specific-CD31 (Dako Corp., Carpinteria, CA), mouse specific-CD68 (Abcam), and mouse specific-IgE receptor (eBioscience, San Diego, CA). Nkx3.1 antibody was a gift from Dr. Edward P. Gelmann at Columbia University, New York. The slides were then washed and incubated in a biotinylated secondary antibody at room temperature for 30 minutes, washed, and incubated again at room temperature for another 30 minutes in peroxidase-conjugated streptavidin. Color was developed with 3,3-diaminobenzidine (DakoCytomation California, Inc., Carpinteria, CA). Counter staining was performed with hematoxylin. For double immunofluorescence staining, Alexa 488 goat antimouse (Invitrogen, Carlsbad, CA) and Alexa 555 goat antirabbit (Invitrogen) were used as secondary antibodies. Proliferation or apoptotic index, defined as percentages of proliferating or apoptotic cells, was established by counting the number of Ki-67- or cleaved caspase 3-positive cells as well as the total number of epithelial cells in ten $40 \times$ microscopic fields for each tissue.

\section{Testosterone Assay}

Mouse serum testosterone concentrations were measured by using the Testosterone EIA kit (Cayman Chemical Company, Ann Arbor, MI). The assay was performed according to the manufacturer's instructions. Briefly, 50 $\mu \mathrm{l}$ of each mouse serum sample in duplicate were incu- bated at room temperature with $50 \mu$ l of Testosterone Antiserum and $50 \mu \mathrm{l}$ of Testosterone AChE Tracer on an orbital shaker for 2 hours. After washing, $200 \mu$ l of Ellman's Reagent were added to each well for color development. The plate was read at a wavelength of $405 \mathrm{~nm}$. Testosterone concentration, in picogram per milliliter, was calculated and determined by using the formula provided by the manufacturer. Statistical significance was determined by using Student's t-test.

\section{Results \\ Establishment of Tissue Grafts, Castration, and Restoration of Androgen}

TSGs were established from human prostate tissues obtained from two radical prostatectomy specimens by precision-cutting and subrenal implantation. We used a new severe combined immunodeficiency mouse model developed by crossing mice lacking the common cytokine receptor $\gamma$ chain with mice lacking the RAG2, which has proven experimentally useful for supporting in vivo growth of cancer cells traditionally difficult to establish as xenografts because these mice lack not only $T$ and $B$ cells but also natural killer cells. ${ }^{21,22}$ Fifteen tissue slices (300- $\mu \mathrm{m}$ thick and 5-mm in diameter) were obtained from each specimen. As outlined in Figure 1A, in each experiment, 15 tissue slices were implanted into the left kidneys of (RAG2) ${ }^{-1-} \gamma \mathrm{C}^{-1-}$ mice (1 slice/mouse) supplemented with testosterone at the time of implantation. TSGs were allowed to establish for a month, at which time three mice were sacrificed as controls to examine the viability, histology, and protein expression of TSGs. Nine of the remaining 12 mice were castrated, and the other three mice were left intact as controls. One month after castration, three castrated mice were sacrificed and TSGs were harvested. Meanwhile, testosterone pellets were implanted under the skin of another three castrated mice to restore androgen. At the end of the experiment ( 2 months after castration), the remaining mice were sacrificed including castrated mice with or without androgen restoration and mice that were intact as controls.

At 1 month after implantation, TSGs were approximately the same size as before implantation (Figure 1B).

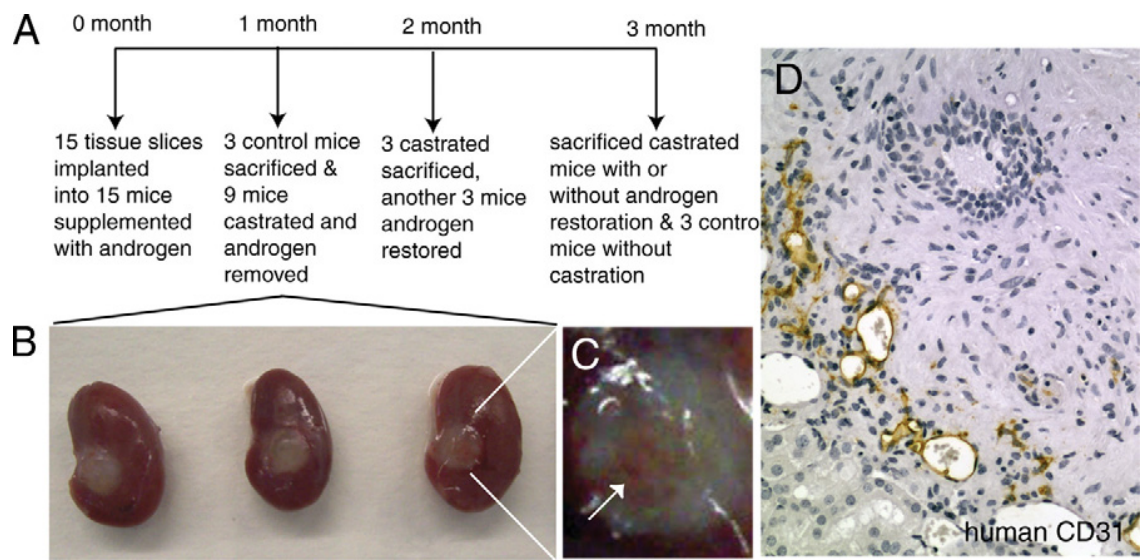

Figure 1. Establishment of tissue grafts, castration, and restoration of androgen. A: Schematic diagram of the experimental design. B: Tissue slice grafts under the renal capsule of mouse kidneys harvested at 1 month after implantation. C: A zoomed in image of the right most TSG shown in $\mathbf{B}$ with an arrow pointing to the vasculature in the TSG. D: Immunohistochemistry using human-specific antibody against CD31 demonstrated the presence of human endothelial cells in TSGs. 


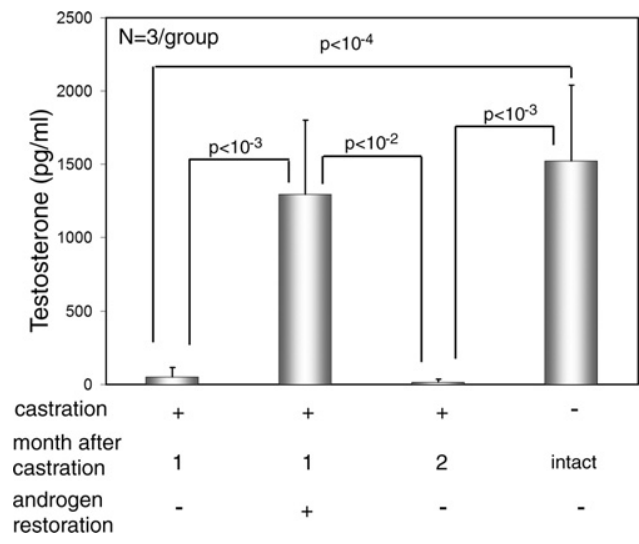

Figure 2. Testosterone levels determined by enzyme-linked immunosorbent assay in mice with castration for 1 month but without androgen restoration, mice with castration for one month and androgen restoration, mice with castration for two months but without androgen restoration, and control mice without androgen supplementation or castration are shown. Statistical significance was determined by Student's $t$-test.

Vascularization of the TSGs was apparent (Figure 1C). Immunohistochemistry using human-specific CD31 antibody demonstrated that a considerable amount of the vasculature present in TSGs after 1 month of implantation was lined by endothelial cells of human origin. This observation is consistent with a previous report that the majority of the vessels in primary xenografts of benign and malignant prostate tissue were lined with human endothelial cells throughout a 30-day study period. ${ }^{11}$ Interestingly, similar results were observed in TSGs even after 3 months of implantation, demonstrating the persistence of human endothelial cells in prostate TSGs.

The level of testosterone in mice 1 month after castration decreased $96 \%$ compared with that in intact mice, from a mean of $1522 \mathrm{pg} / \mathrm{ml}$ in intact animals to $52 \mathrm{pg} / \mathrm{ml}$ in castrated mice (Figure 2). One month after restoration of androgen pellets, testosterone levels in castrated mice became similar to those in intact mice, whereas in mice without androgen restoration, testosterone levels remained low (Figure 2). No significant difference in testosterone levels was observed between intact mice and mice castrated and subsequently implanted with androgen pellets. The testosterone level in castrated mice was $\sim 10$-fold lower than the most commonly used cut-off point of testosterone values to define castration in humans $(500 \mathrm{pg} / \mathrm{ml}){ }^{23,24} \mathrm{In}$ addition, androgen restoration increased the level of testosterone to $1292 \mathrm{pg} / \mathrm{ml}$, comparable with that in intact mice with androgen supplementation.

\section{TSGs Maintain Appropriate Histology and Protein Expression for up to Three Months}

We examined the histology and protein expression of cell type-specific markers in TSGs harvested 1 month after implantation. As shown in Figure 3, the implanted tissue slices contained both normal and cancerous components. The normal glands showed two layers of epithelial cells, the inner secretory and the outer basal cells. The inner layer of cells expressed classical secretory cell

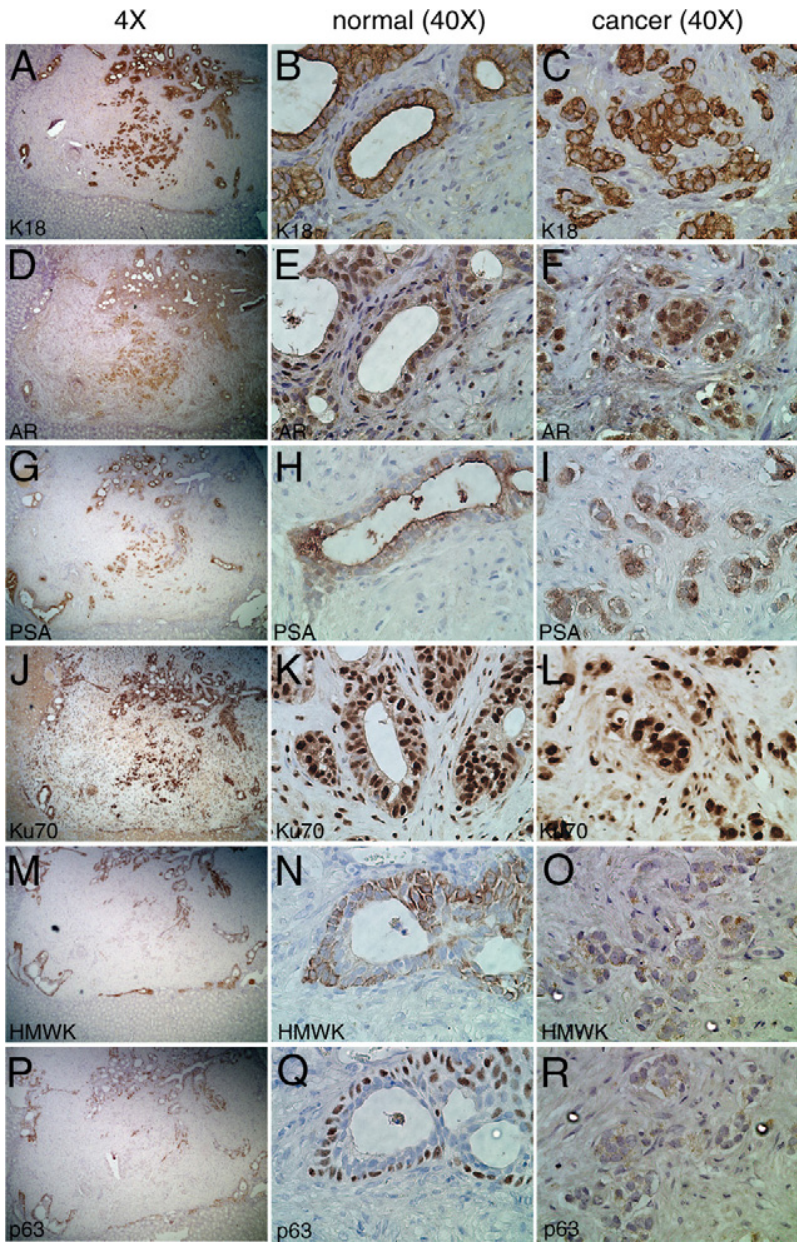

Figure 3. Expression of cell-type specific markers in TSGs harvested at one month after implantation by immunohistochemistry. $\mathbf{A}, \mathbf{D}, \mathbf{G}, \mathbf{J}, \mathbf{M}$, and $\mathbf{P}$ were low magnification $(\times 4)$ images of the same area of the TSG in serial sections stained with different antibodies. The junction of TSG versus mouse kidney was clearly identifiable. Magnification for the rest of the images was $\times 40$. Cytoplasmic staining of K18 and PSA was observed in secretory cells of the normal glands ( $\mathbf{B}$ and $\mathbf{H}$, respectively) and cancer cells ( $\mathbf{C}$ and $\mathbf{I}$, respectively). Nuclear staining of AR was detected in secretory cells of the norma glands (E) and cancer cells (F). Cells of human origin were distinguished from host cells by strong nuclear presence of Ku70 in normal glands (K) and cancer cells (L). Basal epithelial cell markers, HMWK and p63, were expressed in the basal epithelial cells of normal glands ( $\mathbf{N}$ and $\mathbf{Q}$, respectively), but not in cancer cells ( $\mathbf{O}$ and $\mathbf{R}$, respectively).

markers including K18, AR, and PSA. Specifically, strong K18 staining was observed in the cytoplasm (Figure 3, A and $B$ ). These cells also showed nuclear staining of AR (Figure 3, D and E) and cytoplasmic PSA staining (Figure 3, $\mathrm{G}$ and $\mathrm{H}$ ). In contrast, the outer layer of cells was positive for typical basal cell markers including p63 and HMWK recognized by antibody 903 , which is widely used to differentiate benign glands from malignant glands in prostate needle biopsies based on the fact that cancerous glands lose basal cells. The intense signal of HMWK was seen in the cytoplasm of the outer cell layer (Figure 3, $\mathrm{M}$ and $\mathrm{N}$ ), whereas p63 staining in these cells was nuclear (Figure 3, P and Q). In addition, antibody against Ku70 was used to distinguish human versus mouse cells. Both the inner and outer epithelial cell layers displayed strong nuclear staining of Ku70, whereas mouse cells showed background level staining in the cytoplasm (Fig- 


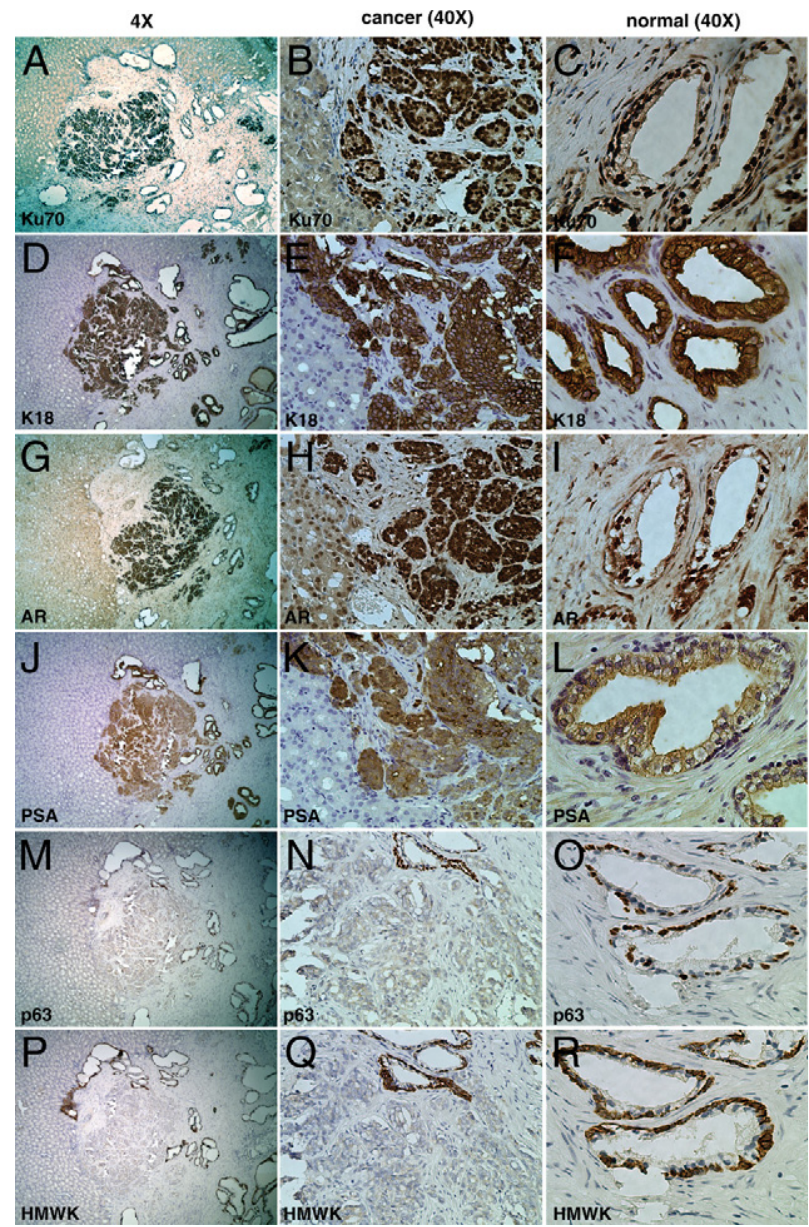

Figure 4. Expression of cell-type specific markers in TSGs harvested at three months after implantation by immunohistochemistry. $\mathbf{A}, \mathbf{D}, \mathbf{G}, \mathbf{J}, \mathbf{M}$, and $\mathbf{P}$ were low magnification $(\times 4)$ images of the same area of the TSG in serial sections stained with different antibodies. The junction of TSG versus mouse kidney was clearly identifiable. Magnification for the rest of the images was $\times 40$. Cells of human origin were distinguished from host cells by strong nuclear presence of Ku70 in cancer cells (B) and normal glands (C). Cytoplasmic staining of K18 and PSA was observed in cancer cells (E and $\mathbf{K}$ respectively) and secretory cells of the normal glands (F and $\mathbf{L}$, respectively). Nuclear staining of AR was detected in secretory cells of cancer cells $(\mathbf{H})$ and the normal glands (I). Basal epithelial cell markers, HMWK and p63, were expressed in the basal epithelial cells of normal glands ( $\mathbf{O}$ and $\mathbf{R}$, respectively), but not in cancer cells ( $\mathbf{N}$ and $\mathbf{Q}$, respectively).

ure 3, $\mathrm{J}$ and $\mathrm{K}$ ). It was noted that many Ku70-positive cells were present in the stroma of TSGs maintained in the host for 1 month (Figure 3, K and L) as well as for 3 months (Figure 4, B and C), suggesting that human prostatic stromal cells survived implantation similar to the epithelial cells. Overall, these results indicated that normal prostate glands maintained appropriate histomorphology, cell composition, and protein expression in TSGs at 1 month postimplantation.

High grade cancer (Gleason grade 4) was also identifiable in this TSG (Figure 3), appearing as an irregular mass of neoplastic cells with little or no gland formation. These cancer cells were strongly positive for $\mathrm{K} 18$ and Ku70 (Figure 3, C and L). In addition, these cells showed nuclear staining of AR and cytoplasmic PSA (Figure 3, F and I). Moreover, these cells were negative for the basal epithelial cell markers HMWK and p63 (Figure 3, O and
R). These results demonstrated that grade 4 PCa maintained its histopathological and molecular characteristics in our TSG model.

We further examined TSGs maintained for 3 months under the renal capsule of (RAG2) $)^{-1-} \gamma \mathrm{C}^{-1-}$ mice. Cancer (Gleason grade 4) surrounded by normal glands was present in the graft shown in Figure 4. Cells within this cancer were stained intensely with antibodies against Ku70 (Figure 4, A and B), K18 (Figure 4, D and E), and AR (Figure 4, $G$ and $H$ ). These cells also showed high expression of PSA (Figure 4, $\mathrm{J}$ and $\mathrm{K}$ ), but no staining for p63 (Figure 4, M and N) or HMWK (Figure 4, $\mathrm{P}$ and Q). The lack of staining for HMWK and p63 was not due to technical failure because the normal glands adjacent to the cancer were strongly positive for p63 (Figure 4N) and HMWK (Figure 4Q) in the basal epithelial cells. As expected, the normal glands in this TSG consisted of secretory epithelial cells expressing K18 (Figure 4F), AR (Figure 4I), and PSA (Figure 4L), and basal epithelial cells expressing p63 (Figure 4O) and HMWK (Figure 4R). These results demonstrated that our TSG model preserved the histological and molecular characteristics of normal prostate epithelial cells and high grade PCa for up to 3 months in intact mice.

To evaluate inflammatory infiltrates in TSGs, we performed immunocytochemistry to identify macrophages using a monoclonal antibody against mouse CD68 and mast cells using anti-IgE receptor. Neither macrophages nor mast cells were detected in TSGs at any time points (data not shown). In addition, no neutrophils were present in TSGs as determined by Giemsa staining (data not shown). Our results indicated little if any inflammatory infiltrates in this TSG model.

\section{Proliferation and Apoptosis in TSGs}

We performed immunohistochemistry by using antibodies against $\mathrm{Ki}-67$ and cleaved caspase-3 to evaluate proliferation and apoptosis, respectively, at the different points of the experiments. As shown in Table 1, benign epithelial cells showed a proliferation index (percentage of Ki-67-positive cells) of 1.28 and 0.55 at 1 and 3 months after implantation, respectively. Consistent with previous findings, ${ }^{25}$ cancer epithelial cells showed a higher proliferation index of 2.08 and 1.69 at 1 and 3 months after implantation. Castration decreased the proliferation index of benign cells to 0.31 and 0.29 after 1 and 2 months of androgen withdrawal, respectively, whereas androgen supplementation restored the proliferation index to 1.64 . For apoptosis, the benign epithelial cells showed $0.31 \%$ and $0.47 \%$ cleaved caspase-3-positive cells after 1 and 3 months of implantation, whereas cancer cells showed a much lower apoptotic index of 0.024 and 0.047 , respectively. This is consistent with previous findings that apoptosis was decreased in PCa compared with benign prostatic cells. ${ }^{26}$ We did not observe an increased apoptotic index in TSGs after castration, which may be explained by the time points of our observations. Previous studies showed an increased apoptosis in human prostate tissue grafts after castration that returned to baseline within 21 days. ${ }^{13}$ 
Table 1. Proliferation and Apoptotic Indices of Prostate Epithelial Cells in TSGs

\begin{tabular}{|c|c|c|c|c|c|c|c|c|c|c|}
\hline \multirow[b]{2}{*}{ Time point } & \multicolumn{2}{|c|}{$\begin{array}{l}\text { Number of cells } \\
\text { counted }\end{array}$} & \multicolumn{2}{|c|}{$\begin{array}{l}\text { Number of Ki- } 67 \\
\text { positive cells }\end{array}$} & \multicolumn{2}{|c|}{$\begin{array}{c}\text { Number of } \\
\text { caspase-3 } \\
\text { positive cells }\end{array}$} & \multicolumn{2}{|c|}{$\begin{array}{l}\text { Proliferation } \\
\text { index, \% }\end{array}$} & \multicolumn{2}{|c|}{$\begin{array}{l}\text { Apoptotic } \\
\text { index, \% }\end{array}$} \\
\hline & Benign & Cancer & Benign & Cancer & Benign & Cancer & Benign & Cancer & Benign & Cancer \\
\hline 1 month intact & 2576 & 817 & 33 & 17 & 8 & 2 & 1.28 & 2.08 & 0.31 & 0.024 \\
\hline 1 month after castration & 976 & NA & 3 & NA & 1 & NA & 0.31 & NA & 0.10 & NA \\
\hline 2 months after castration & 1017 & NA & 3 & NA & 2 & NA & 0.29 & NA & 0.20 & NA \\
\hline $\begin{array}{l}2 \text { months after castration with } \\
\text { androgen restoration }\end{array}$ & 608 & NA & 10 & NA & 0 & NA & 1.64 & NA & 0 & NA \\
\hline 3 months intact & 1274 & 2125 & 7 & 36 & 6 & 1 & 0.55 & 1.69 & 0.47 & 0.047 \\
\hline
\end{tabular}

Proliferation or apoptotic index, defined as percentages of proliferating or apoptotic cells, was established by counting the number of Ki-67-positive or cleaved caspase 3-positive cells as well as the total number of epithelial cells in ten $40 \times$ microscopic fields for each tissue.

Therefore, it is not unexpected that the apoptotic indices we observed 1 and 2 months after castration were comparable with the baseline.

\section{Androgen-Regulated Protein Expression Diminished After Androgen Ablation and Was Restored After Androgen Repletion in TSGs}

To determine the effects of androgen ablation on human prostatic epithelial cells in our model, we examined the histology and protein expression of TSGs in mice with castration levels of androgen (Figure 5). One month after castration, two types of morphology were seen in TSGs.

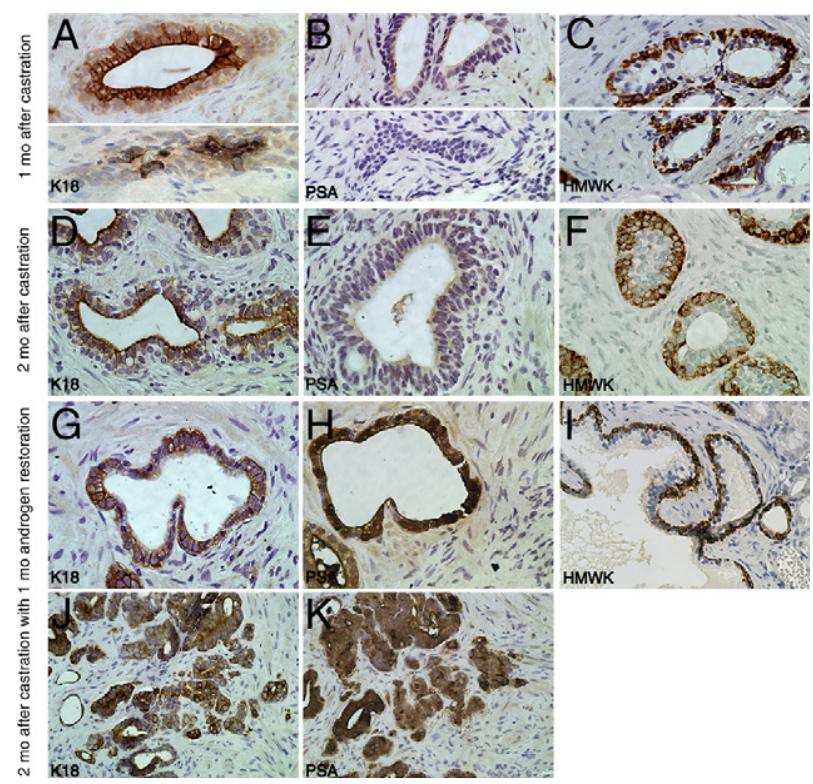

Figure 5. Androgen-regulated protein expression diminished after androgen ablation and was restored after androgen repletion in TSGs as determined by immunohistochemistry. One month (mo) after castration, K18expressing cells were located in the inner cell layer of normal glands (A, top) and in clusters of cells resembling involuting glands (A, bottom). No PSApositive cells were seen in either normal $(\mathbf{B}$, top) or involuting glands $(\mathbf{B}$, bottom). HMWK was expressed in the outer layer of normal glands (C, top) and most of the cells in the cluster of cells resembling involuting glands (C, bottom). Similarly, two months after castration, K18-expressing cells (D) and HMWK-expressing cells (F) were observed in the inner and outer layers of normal glands, respectively, whereas no PSA expression was detected (E). After androgen restoration, PSA expression was observed in the inner layer of normal glands $(\mathbf{H})$ and cancer cells $(\mathbf{K})$. K18-positive cells were also seen in these compartments ( $\mathbf{G}$ and $\mathbf{J}$ ), whereas HMWK-positive cells were in the outer layer of normal glands $(\mathbf{I})$. Original magnification $=\times 40$.
The majority of benign glands were composed of two cell layers. The inner cell layer of these normal-looking glands showed strong staining of $\mathrm{K} 18$ in the cytoplasm (Figure $5 \mathrm{~A}$, top), but little or no staining of PSA (Figure 5B, top). The outer cell layer of these glands was positive for HMWK (Figure 5C, top). A small subset of epithelial cells was present as clusters of cells with a morphology resembling involuting glands (Figure 5, A-C, bottom). Cells in the middle of these clusters showed intense staining for cytokeratin 18 (Figure 5A, bottom). The majority of cells in these clusters were positive for HMWK (Figure $5 \mathrm{C}$, bottom). No PSA expression was seen in these cell clusters (Figure 5B, bottom). These results suggest that androgen ablation abolished PSA expression in secretory epithelial cells and caused involution of a subset of glands. However, the majority of glands remained intact with K18-expressing secretory and HMWK-expressing basal epithelial cells.

To determine the effects of androgen restoration on TSGs subjected to 1 month of androgen ablation, we compared the histology and protein expression of TSGs with or without androgen restoration. TSGs maintained in castrated mice for 2 months without androgen restoration showed similar histology and protein expression to grafts maintained for 1 month after castration, except fewer involuting-like glands were observed after 2 months. Almost all glands were normal-looking with K18-positive and PSA-negative secretory epithelial cells, and HMWK-positive basal epithelial cells (Figure 5, D-F). In contrast, after 1 month of androgen restoration to the castrated mice, the secretory cells showed intense PSA staining (Figure $5 \mathrm{H}$ ). K18 staining in secretory cells (Figure $5 \mathrm{G}$ ) and HMWK staining in basal epithelial cells (Figure 5I) were similar to those in grafts without androgen restoration. Moreover, high grade cancer cells in TSGs with androgen restoration were clearly identifiable and expressed K18 and PSA (Figure 5, J and K). Taken together, our results demonstrated that androgen restoration induced PSA expression in normal secretory cells and cancer cells previously subjected to androgen ablation.

\section{Responses of Human Prostate to Hormonal Therapy}

To compare the effects of androgen ablation on TSGs to those that occur in the human prostate in men subjected 

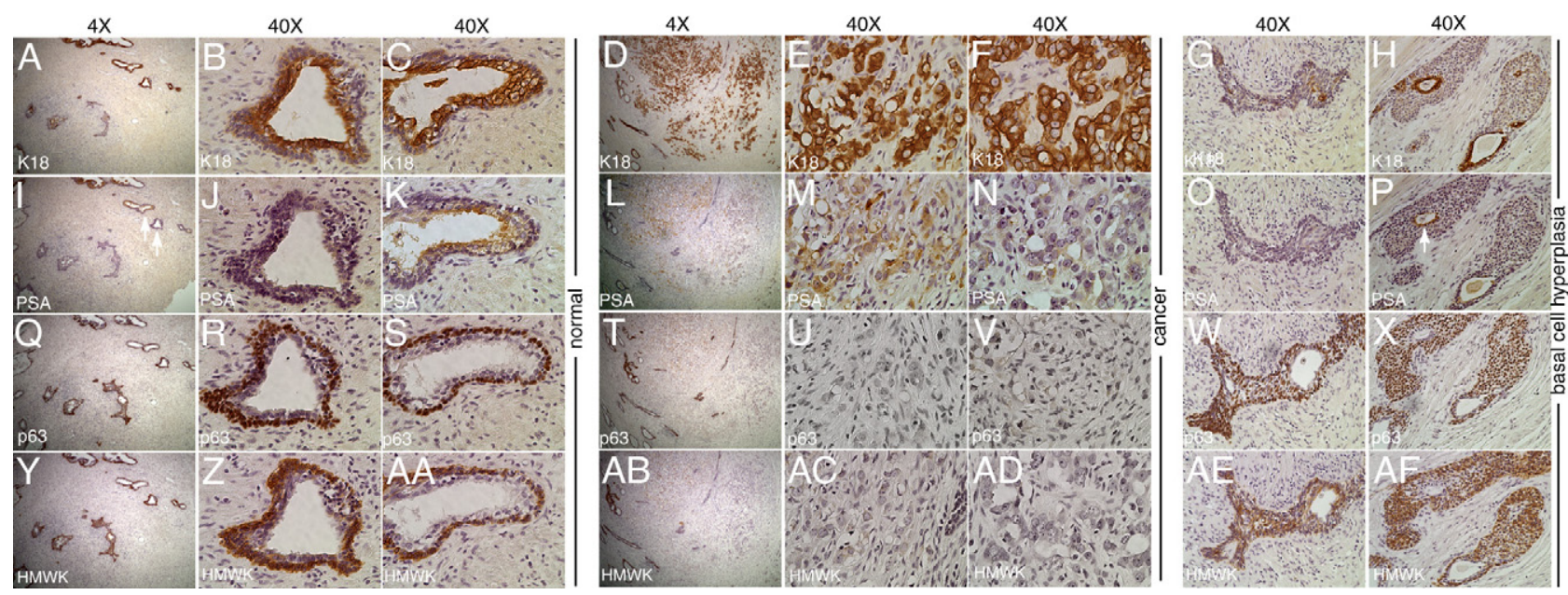

Figure 6. Effects of androgen ablation therapy on human prostate. Magnification for $\mathbf{A}, \mathbf{D}, \mathbf{I}, \mathbf{L}, \mathbf{Q}, \mathbf{T}, \mathbf{Y}$, and $\mathbf{A B}$ is $\times 4$, and for the rest of the images is $\times 40$. In human prostate with short-term androgen ablation, normal glands with K18-expressing secretory cells (B and $\mathbf{C})$ and p63 (R and $\mathbf{S})$ and HMWK-expressing (Z and AA) basal cells were clearly identifiable. PSA expression in secretory cells was heterogeneous with intermediate (K) to no (J) staining. Involuting glands consisted of scattered K18-positive cells (G) and many p63- and HMWK-positive cells (W and AE, respectively). No PSA-positive cells were seen in these glands (O). The remaining cancer cells were K18-positive (E and F), p63-negative (U and V), and HMWK-negative (AC and AD). Similar to normal secretory cells, both positive- and negative-PSA staining were seen ( $\mathbf{M}$ and $\mathbf{N}$, respectively) in cancer cells. Note that the cancer cells with positive and negative PSA staining were adjacent to each other (L). Basal cell hyperplasia was observed in a subset of glands with multilayered p63-positive (X), HMWK-positive (AF) basal cells surrounding a single layer of K18-positive $(\mathbf{H})$, and PSA-negative or -positive secretory cells (P).

to androgen ablation, we examined histology and protein expression in human prostates removed by radical prostatectomy following neoadjuvant androgen ablation (Flutamide or Lupron treatment) of 6 to 10 weeks in duration. Three archival specimens were chosen (Figure 6). Both normal glands and high grade cancers of Gleason pattern 4 and 5 were identifiable in the tissues. The normal glands showed strong cytoplasmic expression of K18 in secretory epithelial cells (Figure 6, A-C). Consistent with the observation in TSGs subjected to androgen ablation, little or no PSA staining was observed in the majority of the inner cell layers of the normal glands (Figure 6, I and J). However, in a subset of glands, faint to intermediate PSA staining was present (top of Figure 6I, and Figure $6 \mathrm{~K}$ ). Note that a gland with no PSA staining in Figure $6 \mathrm{~J}$ is adjacent to one with intermediate PSA staining in Figure 6K (arrows in Figure 6I). The basal epithelial cells of the normal glands were positive for p63 (Figure 6, Q-S) and HMWK (Figure 6, Y-AA). The high grade cancer cells in two adjacent foci resembled normal secretory epithelial cells in that they showed strong staining of K18 (Figure 6, D-F) and no staining of HMWK (Figure 6, AB-AD) or p63 (Figure 6, T-V). However, these two loci showed differential expression of PSA (Figure 6, L-N). One had no PSA staining (Figure $6 \mathrm{~N}$ ) and the other had intermediate staining (Figure 6M). These observations suggest that androgen ablation in human PCa patients abolishes some but not all of PSA expression, and that many normal secretory epithelial cells and cancer cells remain viable.

Atrophy and basal cell hyperplasia were also observed after neoadjuvant androgen ablation. Cell clusters resembling involuting glands were clearly identifiable. Specifically, some clusters had a few K18-positive secretory epithelial cells as a solid mass without lumen in the middle of the cluster (Figure 6G) surrounded by p63- and HMWK-positive basal epithelial cells (Figure 6, W and $A E)$. No PSA-positive cells were observed in these invo- luting glands (Figure 60). Other cell clusters retained a single layer of K18-positive secretory epithelial cells forming a lumen together with multiple layers of basal epithelial cells that were HMWK- and p63-positive (Figure $6 \mathrm{H}$, $X$, and $A F)$. The K18-positive cells lining the lumen were also PSA-positive (arrow in Figure 6P). Cells that were K18-positive did not express p63 or HMWK, and vice versa (Figure 6, $\mathrm{X}$ and $\mathrm{AF}$ ). These results suggest that androgen ablation led to diminished PSA expression in secretory epithelial cells as well as glandular involution and basal cell hyperplasia.

\section{Castration-Resistant Nkx3.1-Positive Cells in TSGS}

Nkx3.1, an androgen regulated gene, has been implicated as a tumor suppressor. ${ }^{27,28}$ A recent study reported the existence of a rare population of castrationresistant Nkx3.1-positive cells in mice that serve as both tissue-regenerating stem cells and cells of origin for murine $\mathrm{PCa} .{ }^{29}$ We examined Nkx3.1 expression by immunocytochemistry by using a rabbit polyclonal antibody (Figure 7). In TSGs maintained in control mice, strong nuclear staining in all luminal cells was observed (Figure 7A). In castrated mice, only rare luminal cells were positive for Nkx3.1 and they often clustered together (Figure 7B, right panel). In involuting glands, the remaining luminal cells were often positive for Nkx3.1 (Figure 7B, left panel). After androgen restoration in castrated mice, $\mathrm{Nkx3} .1$ staining became uniform in luminal cell layers (Figure 7C). Double immunofluorescence staining using antibodies against HMWK (Figure 7, D and F) or p63 (Figure 7E) and Nkx3.1 showed that in human prostates removed by radical prostatectomy following neoadjuvant androgen ablation, a small population of luminal cells expressed Nkx3.1, whereas the majority of luminal cells were negative. Our 

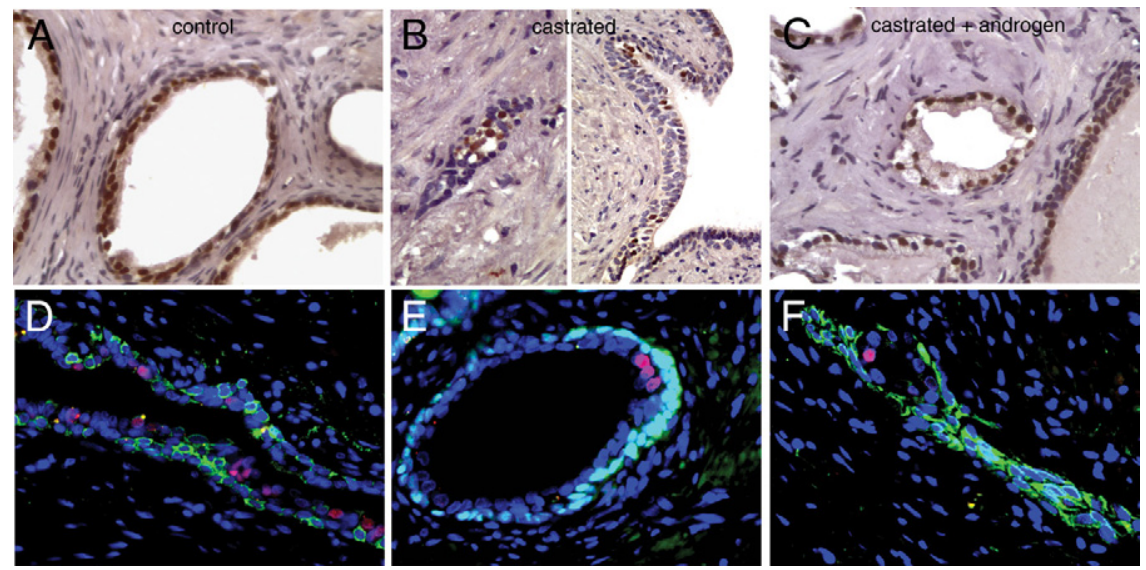

Figure 7. Expression of Nkx3.1 in TSGs and human prostate after androgen ablation. Nuclear staining of Nkx3.1 was observed in all luminal cells in TSGs 1 month after implantation in intact mice (A) and TSGs in mice with androgen restoration after castration (C). Only rare NKx3.1positive cells were detected in TSGs maintained in mice with castration only (B). Double immunoflurescence staining using antibodies against HMWK (green in $\mathbf{D}$ and $\mathbf{F}$ ) or p63 (green in $\mathbf{E}$ ) and Nkx3.1 (red in D-F) showed a small population of luminal cells expressing Nkx3.1 in human prostates after neoadjuvant androgen ablation. 4',6-diamidino-2-phenylindole was used to stain the nucleus (blue) in D-F. Original magnification $=\times 40$ results demonstrated the existence of castration-resistant Nkx3.1-expressing cells in human prostate and in TSGs. Therefore, our TSG model provides a unique tool to further investigate whether these cells represent a type of stem cell that can give rise to $\mathrm{PCa}$ in humans.

\section{Other Observations in TSGs Maintained in Mice}

While examining the kidneys of mice implanted with TSGs, we noted the presence of a glandular-like structure embedded deep in the parenchyma, remote from the site of implantation of the TSG. This structure, seen in a castrated mouse without androgen restoration, contained human cells positive for Ku70 (Figure 8, A and B). Interestingly, the human cells were organized into a branching morphology with tubules consisting of basal (HMWKand p63-positive; Figure 8, C-F) and luminal (AR- and K18-positive; Figure 8, G-J) cells. This interconnected tubular morphology was similar to that observed in mouse prostate glands arising from a single stem cell as reported in a recent study. ${ }^{30}$ It is possible that this structure originated from a single human prostate stem cell that migrated from the TSG. Alternatively, it may be part of the original graft. However, this possibility seems unlikely because the unique interconnected morphology was not observed in the TSG itself and, in serial sections, there appeared to be no interconnection between the TSG and the tubular structure.

Another interesting observation was the intermingling of human prostate cells with mouse kidney cells at the junction where TSGs met host kidney tissues (Figure 9). The human prostate cells seemed to have "invaded" the kidney tissues as streams of cells from the grafts penetrated into the kidney. These cells were basal epithelial in nature since they showed expression of basal cell markers HMWK (Figure 9, A and B) and p63 (Figure 9, C and $D)$. These occurrences were rare, and more studies are needed to determine the significance of the phenomena.

\section{Discussion}

Prostate tissue grafts previously reported by others were established from minced tissues and, in many cases, were implanted subcutaneously in nude or severe combined immunodeficiency mice. We have improved on these methods by using thin, precision-cut tissue slices and have successfully implanted, under the renal capsule of RAG2- $\gamma \mathrm{C}^{-}$mice, prostate tissue slices containing normal and malignant cells whose behavior was monitored over time. After a period of establishment of $\sim 1$ month, the original histology was regained and maintained for up to 3 months. In addition, the secretory and basal epithelial cells expressed the correct markers specific to their cell types. Moreover, the cancer cells displayed characteristic Gleason patterns and maintained secretory differentiation (expression of $\mathrm{K} 18, \mathrm{AR}$, and PSA). Our study demonstrated the feasibility of generating a relatively large number of TSGs from the same specimen with similar cell composition and histology among control and experimental samples in an in vivo setting. This capability is particularly useful since PCa specimens are becoming smaller due to early cancer detection.

Our model has several advantages over tissue grafts derived from minced tissues. First, precision cutting produces less cell damage than mincing. Second, the implanted tissue slices are of identical and uniform size. Third, slices at 300- $\mu \mathrm{m}$ are within the limits of diffusion and permit optimal exchange of nutrients, oxygen, and drugs between the grafted tissue and the host; this is probably most critical in the first days after implantation, before the host vasculature becomes established within the graft. Fourth, our methodology provides a more accurate assessment of the effects of interventions because tissues from the same specimen with similar cell composition and histology can be used as control and experimental samples. Furthermore, adjacent sections can be frozen and examined before implantation to provide information about cellular composition of the tissue to be implanted.

Our model is designed for the study of benign human prostate tissues as well as primary prostatic adenocarcinomas. A large proportion of PCa research is directed toward metastatic disease, as is appropriate because it is this stage of disease that is lethal. However, it is acknowledged that advanced metastatic cancer is challenging to 


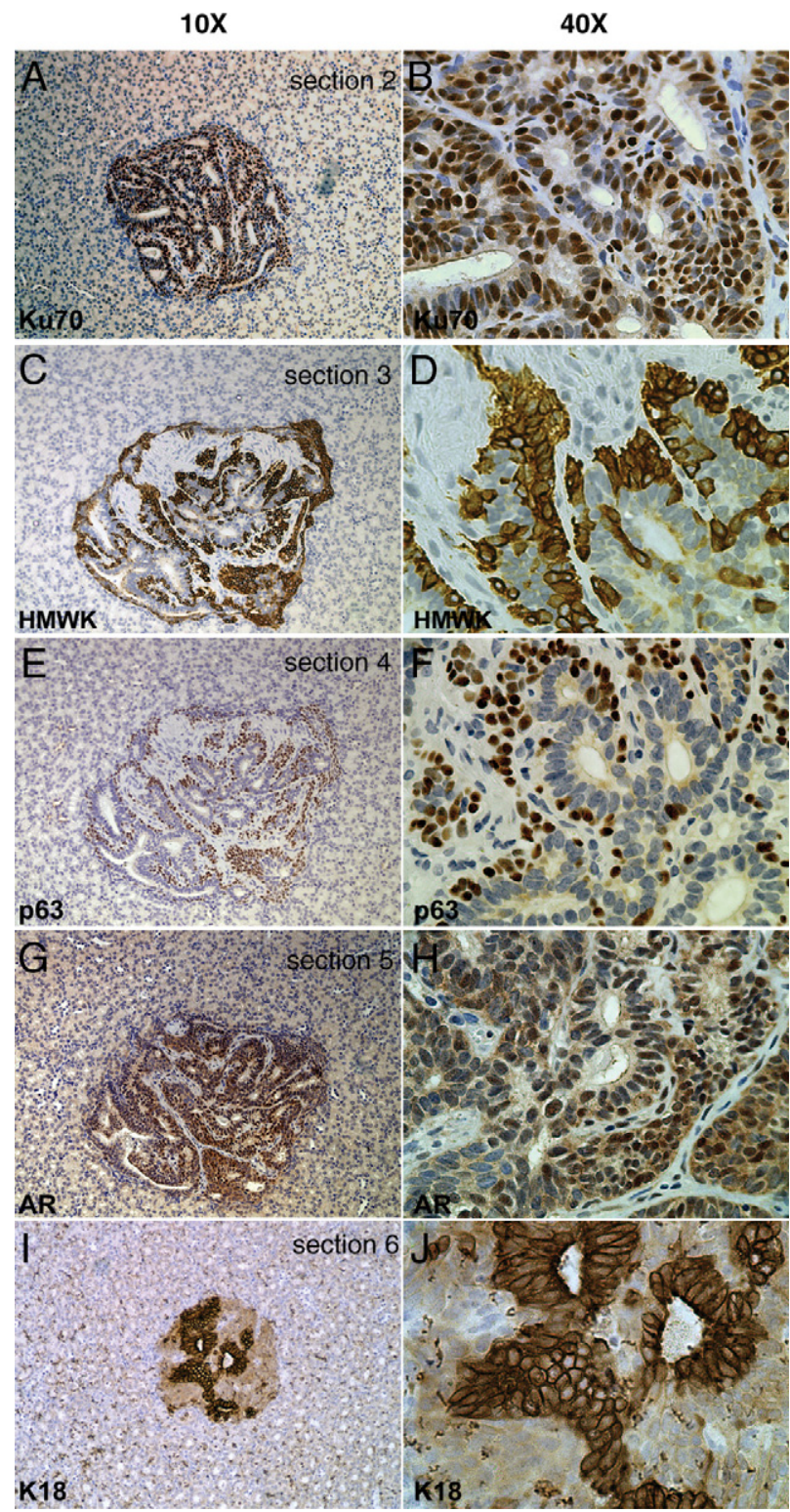

Figure 8. TSG with unique morphology observed in castrated host. An interconnected tubular structure of human origin as demonstrated by nuclear Ku70 staining (A and $\mathbf{B}$ ) was observed. It consisted of basal cells expressing HMWK (C and D) and p63 (E and F), and secretory cells expressing K18 (I and $\mathbf{J})$ and $\operatorname{AR}(\mathbf{G}$ and $\mathbf{H})$. Original magnification $=\times 10(\mathbf{A}, \mathbf{C}, \mathbf{E}, \mathbf{G}$, and $\mathbf{I})$ $\times 40(\mathbf{B}, \mathbf{D}, \mathbf{F}, \mathbf{H}$, and $\mathbf{J})$.

cure or even to effectively treat, and breakthroughs in this area have been disappointingly few and slow to come. ${ }^{31,32}$ At the other end of the spectrum, chemoprevention to block the initiation of cancer or the progression of premalignant lesions or early stage cancer has also met with limited success. ${ }^{33,34}$ Here, we focused on an intermediate stage of the disease: primary adenocarcinomas of the prostate. It is probably this stage of disease that holds the most promise for early detection by imaging or blood tests and for which effective eradication before the development of metastases could significantly decrease mortality rates. In addition, metastatic cancer has been shown to have its origin in primary adenocarcinomas, ${ }^{35,36}$ so understanding and characterizing local-
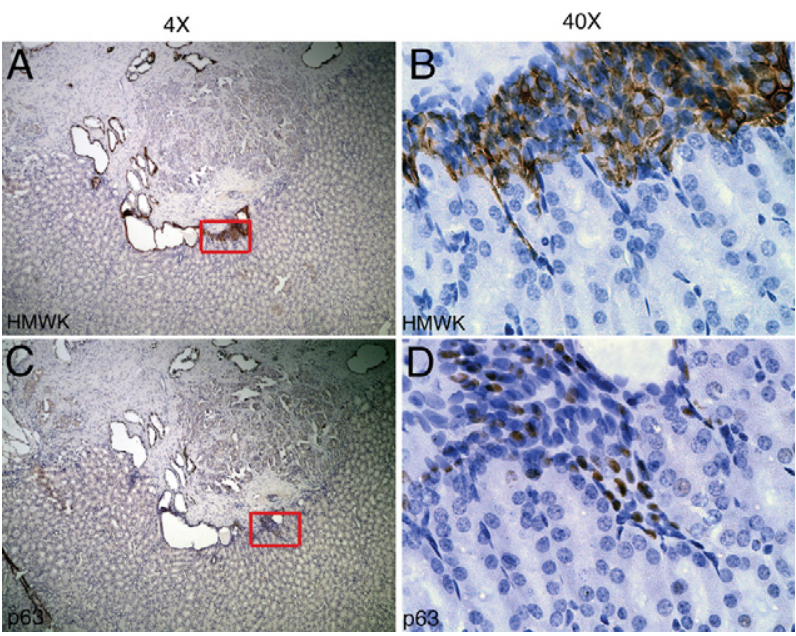

Figure 9. Possible invasion of basal epithelial cells into the host kidney. At the junction of TSG and host kidney, some basal epithelial cells expressing HMWK (A and B) and p63 (C and D) were intermingled with host kidney cells. Original magnification $=\times 4(\mathbf{A}$ and $\mathbf{C}) ; \times 40(\mathbf{B}$ and $\mathbf{D})$. The insets in $\mathbf{A}$ and $\mathbf{C}$ defined the areas that were shown at a higher magnification in $\mathbf{B}$ and D, respectively.

ized cancer is also relevant to metastatic disease. TSGs potentially provide the opportunity to model all stages of disease, from normal tissue to premalignant lesions to well-differentiated cancer and, finally, poorly differentiated cancer.

Although alterations in AR and its activity have been widely implicated in castration- resistant PCa (CRPC), ${ }^{37}$ less is known about androgen action in primary adenocarcinomas. Evidence is accumulating that altered AR and androgen activity, common in CRPC, already start to accrue in primary cancers. High levels of intratumoral androgens have been measured not only in CRPC but in primary cancers as well in men with castrate serum levels of androgen. ${ }^{38,39}$ Similarly, higher levels of testosterone and dihydrotestosterone were found in primary PCa compared with paired benign prostate tissues in eugonadal men. Hierarchical clustering based on expression of steroidogenic enzyme transcripts clearly distinguished primary PCa from benign tissues, suggesting that changes in androgen metabolism occur in clinically localized PCa. ${ }^{40}$ In addition, elevated expression of AR has been associated with higher Gleason grade and decreased biochemical recurrence-free survival. ${ }^{41,42}$ Indeed, primary cancers, especially those of high grade, may be equipped with the same ability to become CRPC as metastases. Therefore, it is understandable that there is interest in using androgen ablation therapy as a neoadjuvant/adjuvant therapy for clinically localized high risk $\mathrm{PCa}$.

However, our knowledge about the response of primary prostatic adenocarcinomas to androgen ablation is limited. The information available so far was mostly derived from the comparison of patient tissues with and without treatment. These studies have shown that androgen ablation decreases prostate volume, PSA expression, and the number of proliferative cells in the majority of patients. ${ }^{43-45}$ In addition, nonmalignant glands showed strong prominence and hyperplasia of the basal epithelial 
cell layer. ${ }^{46}$ Using benign prostate tissue xenografts, Staack et $\mathrm{al}^{13}$ demonstrated that castration led to atrophic glands with flattened luminal cells, increased apoptotic index, decreased AR, and undetectable PSA expression in luminal cells. Wang et al ${ }^{10}$ reported similar changes in both benign and malignant prostate tissue grafts after host castration. Huss et $\mathrm{al}^{12}$ went one step further by stimulating the castrated mice with androgen for 2 days and observed increased cellular proliferation localized in the basal cell layer, consistent with the theory of stem cell-driven repopulation of the epithelial compartment.

In our model, prostate tissues responded to androgen ablation as anticipated. By 1 month after castration of the host mouse, androgen-dependent PSA expression disappeared. When androgen was restored, PSA expression reappeared. It is important to note that normal secretory epithelial cells (K18-positive) did not completely disappear in response to androgen ablation, rather, expression of AR target genes such as PSA diminished. Although this is in contrast to previous reports in rodent prostates that castration led to complete loss of secretory cells, it is exactly representative of the human prostate, where it has been seen in postprostatectomy specimens following short-term neoadjuvant androgen ablation that PSA expression declines but many normal secretory and cancer cells remain. ${ }^{43,45}$ We verified this in our own immunohistochemical analysis of archival prostatectomy specimens obtained from men treated with Lupron or Flutamide for several months before surgery. The differences in the fate of secretory cells after androgen ablation may reflect the differences between rodent and human prostates. The heterogeneity in PSA staining in cancer cells in these specimens suggests that androgen signaling remains in a subset of cancer cells. This may be achieved by a number of mechanisms including increased local production of androgen. The observed PSA expression in a subset of normal secretory cells may be the result of a field effect of androgen production by cancer cells. In any case, our findings show that our novel TSG model has the appropriate characteristics to serve as a useful tool for the investigation of androgen signaling in human prostate tissues in vivo.

Compared with previous reports, our study offers several new insights. First, our study is the first to examine the response of an androgen-regulated gene, PSA, after androgen ablation followed by androgen restoration in a realistic in vivo setting. The reappearance of PSA expression after androgen restoration suggested that both normal and malignant prostate epithelial cells were able to respond to host hormonal stimulation. Second, our study demonstrated that K18-positive secretory cells remained in the tissue grafts postcastration up to 2 months. Compared with the 1 month time point used in previous studies, this result suggested that at least a subset of secretory epithelial cells were able to survive without androgen for a relatively long period of time.

Perhaps the most intriguing observation is the embedded human prostate cells within host kidney that formed interconnected tubular structure. The unique interconnected morphology was not observed in the original TSG itself and, in serial sections, there appeared to be no interconnection between the TSG and the tubular structure. Therefore, it is unlikely that this structure is part of the original TSG. Such morphology has been reported when a single mouse prostate stem cell defined by the phenotype Lin-Sca-1+CD133+CD44+CD117+ generated a prostate with an interconnected branching morphology after transplantation in vivo. ${ }^{30}$ It is possible that the structure we observed was generated from a single stem cell residing in the original TSG initially and migrating into the host kidney. The low frequency of such an observation also fits well with the reported low incidence of stem cells in the human prostate. Moreover, the existence of a rare population of castration-resistant Nkx3.1positive luminal cells also supports this idea. If such cells represent the human counterpart of a rare population of luminal stem cells recently identified in mice that can serve as tissue-regenerating stem cells and a cell of origin for murine $\mathrm{PCa}$, it is expected that such cells would be able to differentiate into prostate glands composed of luminal and basal epithelial cells.

In summary, our TSG model system provides a unique opportunity to address key questions in prostate research such as the role of androgen signaling in primary prostate cancers in a realistic in vivo setting. The model also provides a promising tool for preclinical testing of therapeutic strategies for PCa treatment because tumorgrafts purportedly have much better predictive power than other models currently in use. ${ }^{7}$ Moreover, TSGs could possibly serve as a new model for carcinogenesis. For example, potential carcinogenic factors could be tested for their ability to convert normal tissues to PCa. TSGs can be evaluated in real time to capture any effects of these factors including morphological and molecular changes. Such investigations could provide valuable insights not only into the mechanisms underlying prostate carcinogenesis but also the prevention of PCa.

\section{References}

1. Pienta KJ, Abate-Shen C, Agus DB, Attar RM, Chung LW, Greenberg NM, Hahn WC, Isaacs JT, Navone NM, Peehl DM, Simons JW, Solit DB, Soule HR, VanDyke TA, Weber MJ, Wu L, Vessella RL: The current state of preclinical prostate cancer animal models. Prostate 2008, 68:629-639

2. Sobel RE, Sadar MD: Cell lines used in prostate cancer research: a compendium of old and new lines, part 2. J Urol 2005, 173:360-372

3. Sobel RE, Sadar MD: Cell lines used in prostate cancer research: a compendium of old and new lines, part 1. J Urol 2005, 173:342-359

4. Peehl DM: Primary cell cultures as models of prostate cancer development. Endocr Relat Cancer 2005, 12:19-47

5. Lamb DJ, Zhang L: Challenges in prostate cancer research: animal models for nutritional studies of chemoprevention and disease progression. J Nutr 2005, 135:3009S-3015S

6. Shappell SB, Thomas GV, Roberts RL, Herbert R, Ittmann MM, Rubin MA, Humphrey PA, Sundberg JP, Rozengurt N, Barrios R, Ward JM, Cardiff RD: Prostate pathology of genetically engineered mice: definitions and classification. The consensus report from the Bar Harbor meeting of the Mouse Models of Human Cancer Consortium Prostate Pathology Committee. Cancer Res 2004, 64:2270-2305

7. Garber K: From human to mouse and back: "tumorgraft" models surge in popularity. J Natl Cancer Inst 2009, 101:6-8

8. Garber K: Personal mouse colonies give hope for pancreatic cancer patients. J Natl Cancer Inst 2007, 99:105-107

9. Presnell SC, Werdin ES, Maygarden S, Mohler JL, Smith GJ: Estab- 
lishment of short-term primary human prostate xenografts for the study of prostate biology and cancer. Am J Pathol 2001, 159:855-860

10. Wang Y, Revelo MP, Sudilovsky D, Cao M, Chen WG, Goetz L, Xue H, Sadar M, Shappell SB, Cunha GR, Hayward SW: Development and characterization of efficient xenograft models for benign and malignant human prostate tissue. Prostate 2005, 64:149-159

11. Gray DR, Huss WJ, Yau JM, Durham LE, Werdin ES, Funkhouser WK, Jr., Smith GJ: Short-term human prostate primary xenografts: an in vivo model of human prostate cancer vasculature and angiogenesis. Cancer Res 2004, 64:1712-1721

12. Huss WJ, Gray DR, Werdin ES, Funkhouser WK, Jr., Smith GJ: Evidence of pluripotent human prostate stem cells in a human prostate primary xenograft model. Prostate 2004, 60:77-90

13. Staack A, Kassis AP, Olshen A, Wang Y, Wu D, Carroll PR, Grossfeld GD, Cunha GR, Hayward SW: Quantitation of apoptotic activity following castration in human prostatic tissue in vivo. Prostate 2003, 54:212-219

14. Richter E, Srivastava S, Dobi A: Androgen receptor and prostate cancer. Prostate Cancer Prostatic Dis 2007, 10:114-118

15. Sharifi N, Gulley JL, Dahut WL: Androgen deprivation therapy for prostate cancer. JAMA 2005, 294:238-244

16. Kiviharju-af Hallstrom TM, Jaamaa S, Monkkonen M, Peltonen K, Andersson LC, Medema RH, Peehl DM, Laiho M: Human prostate epithelium lacks Wee1A-mediated DNA damage-induced checkpoint enforcement. Proc Natl Acad Sci USA 2007, 104:7211-7216

17. Blauer M, Tammela TL, Ylikomi T: A novel tissue-slice culture model for non-malignant human prostate. Cell Tissue Res 2008, 332:489-498

18. Parrish AR, Gandolfi AJ, Brendel K: Precision-cut tissue slices: applications in pharmacology and toxicology. Life Sci 1995, 57:1887-1901

19. Kochakian C: The rate of absorption and effects of testosterone propionate pellets on mice. Endocrinology 1941, 28:478-484

20. Ibrahim L, Wright EA: Effect of castration and testosterone propionate on mouse vibrissae. Br J Dermatol 1983, 108:321-326

21. van Rijn RS, Simonetti ER, Hagenbeek A, Hogenes MC, de Weger RA, Canninga-van Dijk MR, Weijer K, Spits H, Storm G, van Bloois L, Rijkers G, Martens AC, Ebeling SB: A new xenograft model for graftversus-host disease by intravenous transfer of human peripheral blood mononuclear cells in RAG2-/- gammac-/- double-mutant mice. Blood 2003, 102:2522-2531

22. Prince ME, Sivanandan R, Kaczorowski A, Wolf GT, Kaplan MJ, Dalerba P, Weissman IL, Clarke MF, Ailles LE: Identification of a subpopulation of cells with cancer stem cell properties in head and neck squamous cell carcinoma. Proc Natl Acad Sci USA 2007, 104:973-978

23. Pathak AS, Pacificar JS, Shapiro CE, Williams SG: Determining dosing intervals for luteinizing hormone releasing hormone agonists based on serum testosterone levels: a prospective study. J Urol 2007, 177:2132-2135; discussion 2135

24. de Jong IJ, Eaton A, Bladou F: LHRH agonists in prostate cancer: frequency of treatment, serum testosterone measurement and castrate level; consensus opinion from a roundtable discussion. Curr Med Res Opin 2007, 23:1077-1080

25. Tamboli P, Amin MB, Schultz DS, Linden MD, Kubus J: Comparative analysis of the nuclear proliferative index (Ki-67) in benign prostate, prostatic intraepithelial neoplasia, and prostatic carcinoma. Mod Pathol 1996, 9:1015-1019

26. Zeng L, Rowland RG, Lele SM, Kyprianou N: Apoptosis incidence and protein expression of p53, TGF-beta receptor II, p27Kip1, and Smad4 in benign, premalignant, and malignant human prostate. Hum Pathol 2004, 35:290-297

27. Mogal AP, van der Meer R, Crooke PS, Abdulkadir SA: Haploinsufficient prostate tumor suppression by Nk×3.1: a role for chromatin accessibility in dosage-sensitive gene regulation. J Biol Chem 2007, 282:25790-25800

28. Lei Q, Jiao J, Xin L, Chang CJ, Wang S, Gao J, Gleave ME, Witte ON, Liu X, Wu H: NKX3.1 stabilizes p53, inhibits AKT activation, and blocks prostate cancer initiation caused by PTEN loss. Cancer Cell 2006, 9:367-378
29. Wang X, Kruithof-de Julio M, Economides KD, Walker D, Yu H, Halili MV, Hu YP, Price SM, Abate-Shen C, Shen MM: A luminal epithelial stem cell that is a cell of origin for prostate cancer. Nature 2009, 461:495-500

30. Leong KG, Wang BE, Johnson L, Gao WQ: Generation of a prostate from a single adult stem cell. Nature 2008, 456:804-808

31. Garmey EG, Sartor O, Halabi S, Vogelzang NJ: Second-line chemotherapy for advanced hormone-refractory prostate cancer. Clin Adv Hematol Oncol 2008, 6:118-122, 127-132

32. Suzuki H, Okihara K, Miyake H, Fujisawa M, Miyoshi S, Matsumoto T, Fujii M, Takihana Y, Usui T, Matsuda T, Ozono S, Kumon H, Ichikawa T, Miki T: Alternative nonsteroidal antiandrogen therapy for advanced prostate cancer that relapsed after initial maximum androgen blockade. J Urol 2008, 180:921-927

33. Jayachandran J, Freedland SJ: Prevention of prostate cancer: what we know and where we are going. Am J Mens Health 2008, 2:178-189

34. Sarvis JA, Thompson IM: Prostate cancer chemoprevention: update of the prostate cancer prevention trial findings and implications for clinical practice. Curr Oncol Rep 2008, 10:529-532

35. Chung LW, Baseman A, Assikis V, Zhau HE: Molecular insights into prostate cancer progression: the missing link of tumor microenvironment. J Urol 2005, 173:10-20

36. Buijs JT, van der Pluijm G: Osteotropic cancers: from primary tumor to bone. Cancer Lett 2009, 273:177-193

37. Mohler JL, Gregory CW, Ford OH, 3rd, Kim D, Weaver CM, Petrusz P, Wilson EM, French FS: The androgen axis in recurrent prostate cancer. Clin Cancer Res 2004, 10:440-448

38. Montgomery RB, Mostaghel EA, Vessella R, Hess DL, Kalhorn TF, Higano CS, True LD, Nelson PS: Maintenance of intratumoral androgens in metastatic prostate cancer: a mechanism for castrationresistant tumor growth. Cancer Res 2008, 68:4447-4454

39. Locke JA, Guns ES, Lubik AA, Adomat HH, Hendy SC, Wood CA Ettinger SL, Gleave ME, Nelson CC: Androgen levels increase by intratumoral de novo steroidogenesis during progression of castration-resistant prostate cancer. Cancer Res 2008, 68:6407-6415

40. Stanbrough M, Bubley GJ, Ross K, Golub TR, Rubin MA, Penning TM, Febbo PG, Balk SP: Increased expression of genes converting adrenal androgens to testosterone in androgen-independent prostate cancer. Cancer Res 2006, 66:2815-2825

41. Wako K, Kawasaki T, Yamana K, Suzuki K, Jiang S, Umezu H, Nishiyama T, Takahashi K, Hamakubo T, Kodama T, Naito M: Expression of androgen receptor through androgen-converting enzymes is associated with biological aggressiveness in prostate cancer. J Clin Pathol 2008, 61:448-454

42. Donovan MJ, Osman I, Khan FM, Vengrenyuk Y, Capodieci P, Koscuiszka M, Anand A, Cordon-Cardo C, Costa J, Scher HI: Androgen receptor expression is associated with prostate cancer-specific survival in castrate patients with metastatic disease. BJU Int 2010, 105:462-467

43. Chang SS, Reuter VE, Heston WD, Hutchinson B, Grauer LS, Gaudin PB: Short term neoadjuvant androgen deprivation therapy does not affect prostate specific membrane antigen expression in prostate tissues. Cancer 2000, 88:407-415

44. Bass R, Perry B, Langenstroer P, Thrasher JB, Dennis KL, Tawfik O, Holzbeierlein J: Effects of short-term finasteride on apoptotic factors and androgen receptors in prostate cancer cells. J Urol 2009, 181: 615-619; discussion 619-620

45. Armas OA, Aprikian AG, Melamed J, Cordon-Cardo C, Cohen DW, Erlandson R, Fair WR, Reuter VE: Clinical and pathobiological effects of neoadjuvant total androgen ablation therapy on clinically localized prostatic adenocarcinoma. Am J Surg Pathol 1994, 18:979-991

46. Vailancourt L, Ttu B, Fradet Y, Dupont A, Gomez J, Cusan L, Suburu ER, Diamond P, Candas B, Labrie F: Effect of neoadjuvant endocrine therapy (combined androgen blockade) on normal prostate and prostatic carcinoma: a randomized study. Am J Surg Pathol 1996, 20:86-93 